\section{Interleukin-34: A Potential Diagnostic and Therapeutic Target for Rheumatoid Arthritis}

\section{To the Editor:}

Recently, we read with great interest the article titled "Increased Levels of Interleukin 34 in Serum and Synovial Fluid Are Associated with Rheumatoid Factor and Anticyclic Citrullinated Peptide Antibody Titers in Patients with Rheumatoid Arthritis," published in The Journal of Rheumatology ${ }^{1}$, showing that serum levels of interleukin 34 (IL-34) were positively correlated with rheumatoid factor (RF) and anticyclic citrullinated peptide antibody (anti-CCP) titers, but not with systemic osteoporosis and radiographic joint damage in rheumatoid arthritis (RA). Further, IL-34 levels were significantly increased in the serum of patients with RA ( $p<0.001)$ or ankylosing spondylitis $(\mathrm{p}<0.001)$ compared with controls ${ }^{2}$. These studies bring new insights that IL-34 may play a crucial role in the pathogenesis of RA, and serum levels of IL-34 may be diagnostic and therapeutic targets in RA.

To date, it is well known that RA is characteristic of the expansion of the synovium and the infiltration of the inflammatory cells coupled with the destruction of adjacent articular cartilage and bone ${ }^{3}$. Although the exact causes of RA remain unknown, immunological dysregulation by inflammatory cytokines has been shown to be involved in driving the inflammation and synovial cell proliferation that result in joint destruction in patients with RA.

IL-34 is a recently discovered cytokine that increases monocyte viability and enhances macrophage proliferation through colony-stimulating factor receptor ${ }^{4}$. It has been reported ${ }^{1,5}$ that elevated levels of IL-34 have been observed in the joint tissue, serum, synovial fluid, and fibroblast-like synoviocytes of patients with RA. Interestingly, elevated levels of IL-34 were also detected in early RA (disease duration $\leq 6 \mathrm{mos})^{2}$ and a significant association was found between IL-34 expression and synovitis severity ${ }^{6}$. Of greatest interest, significant positive correlations were found between IL-34 levels, inflammation variables (such as erythrocyte sedimentation rate and C-reactive protein), antibodies production (such as RF and anti-CCP), and disease activity indexes (such as tender joint count and the Disease Activity Score at 28 joints) ${ }^{7}$. The proinflammatory cytokines play a dual role in the pathogenesis of RA that can promote inflammation and the destruction of bone. It was found that IL-34 increased IL-6 and chemokine levels in human whole blood ${ }^{8}$. Similarly, Moon, et al also agreed that IL-34 concentration in synovial fluid correlated significantly with IL-6 and the receptor activator of nuclear factor- $\mathrm{\kappa B}(\mathrm{NF}-\mathrm{\kappa B})$ ligand levels in $\mathrm{RA}^{1}$. Moreover, Tian, et al showed for the first time that IL-34 induced the production of IL-17 by activated peripheral blood mononuclear cells from patients with $\mathrm{RA}^{7}$. On the other hand, tumor necrosis factor (TNF)- $\alpha$ or IL-1 $\beta$ should stimulate IL-34 expression through the NF- $\mathrm{KB}$ and $\mathrm{c}-\mathrm{Jun} \mathrm{N}$-terminal kinase pathway in synovial fibroblasts ${ }^{6}$. Hwang, et $a l^{5}$ also proved that the production of IL-34 was upregulated by TNF- $\alpha$ in RA. Another study showed that IL-34 could promote osteoclastogenesis in vitro ${ }^{9}$. IL-34 would contribute to the persistent expression of proinflammatory cytokines, and accelerate inflammation and the destruction of bone in RA.

Taken together, available evidence suggests that IL-34 may play a potential role in RA. However, further studies are needed to comprehensively extend the role of IL-34 in RA, and the development of therapeutic agents targeting IL-34 may be a promising diagnostic and therapeutic target for RA.

WEI HE, MSc; XIAO-DI XU, MSc; YI-MAN DONG, BSc; HUA WU, Associate Professor, Department of Pharmacy, Binhu Hospital of Hefei City, The Third Affiliated Hospital of Anhui Medical University, Hefei, China. Address correspondence to Dr. H. Wu, Department of Pharmacy, Binhu Hospital of Hefei City, The Third Affiliated Hospital of Anhui Medical University, 230001, Hefei, Anhui Province, China.

E-mail: wuhuaedu@163.com

\section{REFERENCES}

1. Moon SJ, Hong YS, Ju JH, Kwok SK, Park SH, Min JK. Increased levels of interleukin 34 in serum and synovial fluid are associated with rheumatoid factor and anticyclic citrullinated peptide antibody titers in patients with rheumatoid arthritis. J Rheumatol 2013;40:1842-9.

2. Chang SH, Choi BY, Choi J, Yoo JJ, Ha YJ, Cho HJ, et al. Baseline serum interleukin-34 levels independently predict radiographic progression in patients with rheumatoid arthritis. Rheumatol Int 2014 Jun 11 (E-pub ahead of print).

3. Feldmann M, Brennan FM, Maini RN. Rheumatoid arthritis. Cell 1996;85:307-10.

4. Lin H, Lee E, Hestir K, Leo C, Huang M, Bosch E, et al. Discovery of a cytokine and its receptor by functional screening of the extracellular proteome. Science 2008;320:807-11.

5. Hwang SJ, Choi B, Kang SS, Chang JH, Kim YG, Chung YH, et al. Interleukin-34 produced by human fibroblast-like synovial cells in rheumatoid arthritis supports osteoclastogenesis. Arthritis Res Ther 2012;14:R14.

6. Chemel M, Le Goff B, Brion R, Cozic C, Berreur M, Amiaud J, et al. Interleukin 34 expression is associated with synovitis severity in rheumatoid arthritis patients. Ann Rheum Dis 2012;71:150-4.

7. Tian Y, Shen H, Xia L, Lu J. Elevated serum and synovial fluid levels of interleukin-34 in rheumatoid arthritis: possible association with disease progression via interleukin-17 production. J Interferon Cytokine Res 2013;33:398-401.

8. Eda H, Zhang J, Keith RH, Michener M, Beidler DR, Monahan JB. Macrophage-colony stimulating factor and interleukin-34 induce chemokines in human whole blood. Cytokine 2010;52:215-20.

9. Chen Z, Buki K, Vääräniemi J, Gu G, Väänänen HK. The critical role of IL-34 in osteoclastogenesis. PLoS One 2011;6:e18689.

J Rheumatol 2015;42:3; doi:10.3899/jrheum.141135 